\title{
An overview on the correlation between the economic status of a country and the population's health indicators
}

\author{
Mihai PĂUNICĂ \\ The Bucharest University of Economic Studies, Bucharest, Romania \\ mihai.paunica@cig.ase.ro \\ Alexandru MANOLE \\ "ARTIFEX" University of Bucharest, Bucharest, Romania \\ alex@artifex.org.ro \\ Cătălina MOTOFEI \\ The Bucharest University of Economic Studies, Bucharest, Romania \\ catalina.motofei@cig.ase.ro \\ Gabriela - Lidia TĂNASE \\ The Bucharest University of Economic Studies, Bucharest, Romania \\ gabriela.tanase@cig.ase.ro
}

PICBE |

1058

\begin{abstract}
In this paper, the authors aim to measure the influence of the macroeconomic indicators that characterize a national economy on some key national health indicators. The purpose is to obtain an updated evaluation of the population medical status, under the impact of either growth or economic decline. The analysis focuses especially on Romania but also on other countries, to be able to investigate comparatively national indicators and trends. Multiple data sources have been used for an in-depth analysis, to fit in an appropriate manner the purpose of the study. Static and econometric data analysis software was applied on primary data, as analysis instruments. The correlation coefficient and the regression were the tools used to obtain the study conclusions. We start from the premise that the potential of statistic data sources, combined with the processing power of the data analysis tools would be able to lead to the best result. We have also reviewed the previous studies performed on the same topic and, along with our data, the obtained conclusions should have a certain value and interest not only for current needs and utilization, but also for future researches. The authors are aware of the direct influence between the macroeconomic status (or performance) indicators and the indicators that characterize the health of the population, and will attempt to measure the intensity of this impact on several key selected domains.
\end{abstract}

Keywords: life expectancy, influence, economic, correlation, regression.

\section{Introduction}

Life expectancy, which is a well-known indicator of a region's public health status (Wang et al., 2014), and of the efficiency of the healthcare systems (Asandului et al., 2014; Obrizan \& Wehby, 2018) and of economic development (Obrizan \& Wehby, 2018), has recorded a lot of changes in the last period of time. Although life expectancy at birth has grown in general around the world, the growth is not as high as it should be. Despite the fact that there are numerous factors in the present that influence in a positive manner life expectancy, factors like medical progress, the investments or expenditures in the healthcare system, there are 
also factors that have a negative impact on life expectancy. Among those factors we can include air pollution (often resulting from economic / industrial progress) and new diseases specific to this period of time (strongly related to nutrition, ambient irradiation, stress, etc.).

The objective of the research is to measure the influence of macroeconomic indicators (Gross Domestic Product per capita and government expenditure for health) on the health status of the population.

The review of the literature revealed conflicting results regarding the influence that life expectancy will generate on the GDP (see Echevarría \& Iza, 2006). Some authors report a positive connection, while others a negative one, or a relation in an inversed "U" shape (see Echevarría \& Iza, 2006). The aim in this paper is to see if an increase in GDP will affect in a positive manner the quality of life measured through life expectancy at birth, taking into account that life expectancy was chosen as a representative indicator of the health status of population.

The following research hypotheses were stated, according to the objective of the research:

H1. The life expectancy of the population in the European Union and some member countries (Lithuania, Bulgaria, Romania, Hungary and Slovakia) has a growing trend and is influenced in a positive manner by the economic growth and by the financial efforts allocated by the central government to health sector.

$\mathrm{H} 2$. The influence stated by hypothesis $\mathrm{H} 1$ is different, measured upon gender.

The indicator, as defined by Eurostat, which forms the base of the research and is used in this paper to measure the health condition of the population is the life expectancy in absolute value at birth, for each gender, females and males.

The EU member states were chosen on the following basis: the research focus is Romania, authors' country, and the other countries that present similar values of the average value of the life expectancy, computed from the values recorded in 2016 by the life expectancy (at birth) for females and, respectively, males in those countries (when sorting the data on this average, Romania is placed in the middle of the hierarchy). Furthermore, the comparison with the EU overall indicators offers the possibility to compare the situation of more recent members (all individual countries selected fall within the hierarchy) with the aggregated status at the level of the European Union.

The analysis is performed for the period 1995-2016. Data were collected regarding life expectancy (as a dependent variable) and GDP, health expenditures (as explanatory variables) from the Eurostat database. The trend of the life expectancy was studied by quadratic trend regression, and the multiple regression model was used in order to analyze the influence determined by explanatory factors on life expectancy indicator.

The analysis revealed a positive trend (linear in some cases, quadratic in others), as detailed in the section dedicated to results. A positive influence of GDP per capita was outlined only for Bulgaria and Romania (for females) life expectancy at birth, the health expenditures proved to be not statistically significant. Thus, those results can be considered as an incentive to public authorities from each country in comprehend the importance of taking appropriate measures to stimulate economic growth, all for the health of the people. The authors believe that if public authorities will take into consideration this factor of influence, life expectancy and health of individuals can grow. 
The remaining of the paper is structured as follow: in chapter one, literature review regarding the link between life expectancy and GDP and health expenditures is discussed. In chapter two the authors present the research methodology, data collection and the variable quantification, as well as the structure of the econometric models used. In chapter three, the research results and their signification is discussed. In the finale part of the paper the authors present the conclusions, along with research limitation and future research directions.

\section{Literature review}

In order to achieve the stated objective, the research was focused initially on reviewing the literature in the field of life expectancy. First, the link that previous papers found between life expectancy and economic growth, namely the connection between life expectancy and GDP, as well as income, was studied. In the second part of the review, there are to be presented important findings regarding the impact of investments or expenditures made in the healthcare sector, on life expectancy at birth.

1.1 Life expectancy and economic growth

In theory, life expectancy should be greater for wealthier countries and people. Thus, we expect that an increase in GDP per capita, as a measure of a country well-being, shall have a positively influence on life expectancy.

For China, Wang et al. (2014) positively associate per capita GDP with life expectancy. Life expectancy can increase, at a difference of 10.000 RMB (renminbi), with 0.49 years. Cole's (2019) analysis on 134 developing countries shows that a five year economic growth rate in per capita GDP increases life expectancy and reduces infant mortality. Wang et al. (2015) also show that life expectancy has significant positive correlation with GDP per capita in China, GDP per capita being related with better living conditions and more public investments in the healthcare system. Also for China, according to Xinming et al. (2010), the main obstacles that influence life expectancy are economic factors, such as poverty, education, basic sanitation.

Although a positive influence exists, Cole (2019) emphasizes the fact that the benefits of economic growth on health are decreasing as countries become wealthier or increase their economic development. In other words, if GDP per capita increases, the growth effect is attenuated. Wang et al. (2015) also consider that economic condition may influence in a limited manner human longevity.

1.2 Life expectancy and health-related expenses

Life expectancy is also influenced by the progress or the evolution of the medical field. In theory, a better healthcare system, access to medical care, new cures and better technology can help people to live longer and to have a better quality of life. Eradicating or controlling diseases should increase life expectancy.

Boudoulas et al. (2017) discuss in their paper about the impact on life expectancy determined by evolution of medicine disciplines and the evolution of the technology in the medical field.

They state that as the medical science evolved, there have been changes in the nature and frequency of many diseases, and that the cures developed and the emphasis on a healthier lifestyle resulted in an increase of life expectancy. According to them, life expectancy has increased due to progress in the medical field from 45 years in 1850 to 
approximately 80 years in the present. This statement reveals the importance of medical evolution, emphasizing the necessity of public investment in the health care system.

Thus, we consider that life expectancy can also be influenced by the investments made in the healthcare system and infrastructure. Obrizan \& Wehby (2018) analyze the link between health expenditures and life expectancy. Their result supports the fact that an increase in health expenditures may have a positive impact on life expectancy in countries where there is a low life expectancy. The study performed by Jaba et al. (2014), on 175 world countries, also shows a significant connection between health expenditures and life expectancy at birth. They explain the increase in health expenditures from the last years by the existence of factors such as evolution of medical technologies, high life standards and population ageing.

Asiskovitch (2010) evaluates the influence of the health care systems (measured by national expenditures and taking into account the way that the healthcare systems are financed - public and private funding) on life expectancy for 19 OECD countries. The study shows that there is a marginal impact on life expectancy at birth for both genders and expenditure in the healthcare system is a marginal factor of life expectancy for developing countries. But investments in the healthcare system can influence life expectancy also based on the type or source of financing. Asiskovitch (2010) stated that public funding of the healthcare system has a greater impact on life expectancy than the private funding strategy, which will generate a more modest increase. The same can be concluded from the study performed by Linden \& Ray (2017), which also emphasizes the positive connection between public health expenditures and life expectancy, demonstrating that private expenditures also have importance for life expectancy although they are being driven by public expenditures. Hauck et al. (2016) finds that life expectancy increases with 14.5 month the reduction of HIV virus among children, with 9.4 month by the increase of gender equality, by 6 to 9 month due to political stability, access to clean water and sanitation, primary school enrolment and other factors. Improvements in private health expenditures among other factors will generate an increase in life expectancy of only below 6 months. The authors find no evidence to relate national income, public spending on education and healthcare with population health.

Unfortunately, the healthcare systems around the world are not as efficient as it should be. Asandului et al. (2014) analyze the efficiency of the public healthcare system in Europe for the year 2010 by evaluating the impact that public health expenditure measured as a percentage of GDP, the number of doctors and the number of hospital beds has on life expectancy at birth (number of years that a person is expected to live), health adjusted life expectancy (number of years that a person is expected to live without disability) and infant mortality rate, proving that most of the countries analyzed are inefficient or on the efficiency limit. Also, van den Heuvel \& Olaroiu (2017) consider that health care expenditures, measured as a percentage of the GDP, are not a main determinant of life expectancy, the main influence being held by social protection expenditures.

It's important to notice that although medical evolution can have a positive influence on life expectancy, this impact may be reduce due to the evolution of diseases alongside with the evolution in the medical field. Boudoulas et al. (2017) state that the increase of life expectancy and the medical progress also brings an increase of other specific diseases and the appearance of new diseases that where unknown in the past. Also, according to the 
authors, globalization will also be a factor that will influence the spreading of diseases across continents.

\section{Methodology}

Life expectancy at birth is considered the main indicator of the research, while the influence factors considered are the following:

- Gross Domestic Product per capita and

PICBE | 1062

- General government expenditure by function (COFOG), for health.

The data were extracted from the Eurostat online database, for all indicators, to ensure, via a unitary source, a higher degree of comparability. The datasets analyzed have an annual frequency, covering the interval between 1995 and 2016 (some data are available for 2017 as well, but the authors opted to keep the consistency of the time dimension for all indicators).

The life expectancy data are based on the datasets:

- Healthy life years (from 2004 onwards) [hlth_hlye] and

- Healthy life years (1995 - 2003) [hlth_hlye_h]. follows:

For the European Union, the data related to life expectancy were aggregated as

- between 1995-2001, the values for the European Union (15 countries) member of the geographical dimension of Eurostat's data warehouse;

- for 2002-2009, the set of values corresponding to the European Union (before the accession of Croatia) member;

- for 2010-2016, the values related to the European Union (current composition) member.

The GDP per capita was considered as follows: the values of the indicator were computed based on the Percentage of EU28 total per capita (based on million euro), current prices, as presented by Eurostat (Main GDP aggregates per capita [nama_10_pc]). Thus, for each country, the values, corresponding to the percentages published, were calculated for the purpose of this study. For the European Union, the values for the member European Union (current composition) have been included in the dataset. The variables that reflect the indicators presented in the study are described in Table 1.

Table 1. Codification of variables used in the paper

\begin{tabular}{|l|l|l|l|}
\hline Variable name & Variable description & Measurement unit & $\begin{array}{l}\text { EUROSTAT dataset } \\
\text { code }\end{array}$ \\
\hline $\mathrm{M}_{-}{ }^{* * *}$ & $\begin{array}{l}\text { Life expectancy in absolute value } \\
\text { at birth - males }\end{array}$ & years & $\begin{array}{l}{[\text { hlth_hlye]; }} \\
\text { [hlth_hlye_h] }\end{array}$ \\
\hline $\mathrm{F}_{-}^{* * *}$ & $\begin{array}{l}\text { Life expectancy in absolute value } \\
\text { at birth - females }\end{array}$ & years & $\begin{array}{l}\text { [hlth_hlye]; } \\
\text { [hlth_hlye_h] }\end{array}$ \\
\hline $\mathrm{GC}_{-}{ }^{* * *}$ & $\begin{array}{l}\text { Gross domestic product at market } \\
\text { prices, current prices }\end{array}$ & euro per capita & [nama_10_pc] \\
\hline & $\begin{array}{l}\text { Total general government } \\
\text { expenditure on health, general } \\
\text { government sector, as per } \\
\text { COFOG99 }\end{array}$ & million euro & [gov_10a_exp] \\
$\mathrm{HF}_{-}^{* * *}$ & $\begin{array}{l}\text { Country codes: } \\
\text { EUR: European Union }\end{array}$ & & \\
\hline$* * *$ & & & \\
\hline
\end{tabular}




\begin{tabular}{|l|l|l|l|}
\hline & ROM: Romania & & \\
& BGK: Bulgaria & & \\
HUN: Hungary & & \\
& LIT: Lithuania & & \\
SVK: Slovakia & & \\
\hline
\end{tabular}

Source: Authors' own research, based on Eurostat database metadata.

Subsequent to the stated research hypotheses, the authors have resorted to the analysis of the datasets through the use of statistical (correlation coefficient) and econometric methods (regression, both in its simple and multiple form).

All analyses were performed by using the gretl software instrument (http://gretl.sourceforge.net/).

Considering the main indicators correlated with the research hypotheses (life expectancy), the first step in the analysis was to evaluate their linear/quadratic trend, by applying a multiple linear regression model with the time index and square of time index as independent variables, having the following structure:

$$
Y=\alpha+\beta_{1} * \text { time }+\beta_{2}{ }^{*} s q_{-} \text {time }+\varepsilon
$$

where:

$Y$ : life expectancy;

$\alpha$ : the constant factor;

$\beta_{1}, \beta_{2}$ : regression coefficients;

time: the time index variable;

sq_ time: the square of the time index;

$\varepsilon$ : the error term.

The variables included in the study have been tested for stationarity (ADF-GLS test, with a lag of 1, as data are annual and the number of observation is not very high) and, for several variables, the test proved the non-stationary character. For one or more of the variables defining a country, the null hypothesis of a unit root could not be rejected. Therefore, the datasets were transformed by the first differences of the variables, and then the new differences were tested again with the unit root test. While accepting a significance level of 0.05 , the first differences for the variables $F_{-} L I T, D I S V K, H F_{-} L I T, H F_{-} H U N, H F_{-} S V K$, and $G C_{-} S V K$ were found to be non-stationary. Their second differences, however, are stationary. In order to comply with these results, the entire set of variables for the three countries (Hungary, Lithuania and Slovakia) has been differenced to the second order and subjected to regression, as no cointegration was detected.

The justification for this operation resides in the results of Granger and Newbold (1974), cited by Parker (2019, p. 60), which present strong evidence that regressions involving random walks are spurious when performed on the levels, but not on the differences. Also, according to Woolridge (2012, p. 430), "[...] the usual OLS inference procedures can be very misleading when the variables $y_{t}$ and $x_{t}$ are integrated of order one, or I(1). [...] It is more logical to difference the equation." The exception presented by Parker (2019 p.61), the cointegration, was investigated by drawing the multiple regression models between the initial (non-differenced) variables, saving the residuals (error terms) as individual variables and then using the ADF-GLS test. All results proven that, at confidence level 0.01 , the tau tests are higher than the critical values, therefore the residuals have unit roots. 
The influence of GDP/capita and of General government expenditure by function (COFOG), for health on Life expectancy in absolute value at birth were analyzed by applying the model with the general structure outlined below:

$$
\boldsymbol{Y}=\boldsymbol{\beta}_{1} * \boldsymbol{G C}+\boldsymbol{\beta}_{2} * \boldsymbol{H F}+\varepsilon
$$

where:

$Y$ : life expectancy;

$\beta_{1}, \beta_{2}$ : regression coefficients;

$G C$ : GDP per capita;

$H F$ : health expenses by the public government;

$\varepsilon$ : the error term.

For this model, it can be assumed that the variables are not cointegrated, and thus regression against their first or second level differences can be used. The structure of the model is updated by removing the constant, as suggested in Parker (2019, p. 61).

\section{Results and discussions}

\section{- Analysis of the life expectancy trend}

Even if the life expectancy variables are non-stationary, the graphical representation of their values in figure 1 displays a growth trend, whose nature can be studied versus the actual values, in the authors' opinion, by the regression model described in the previous section.

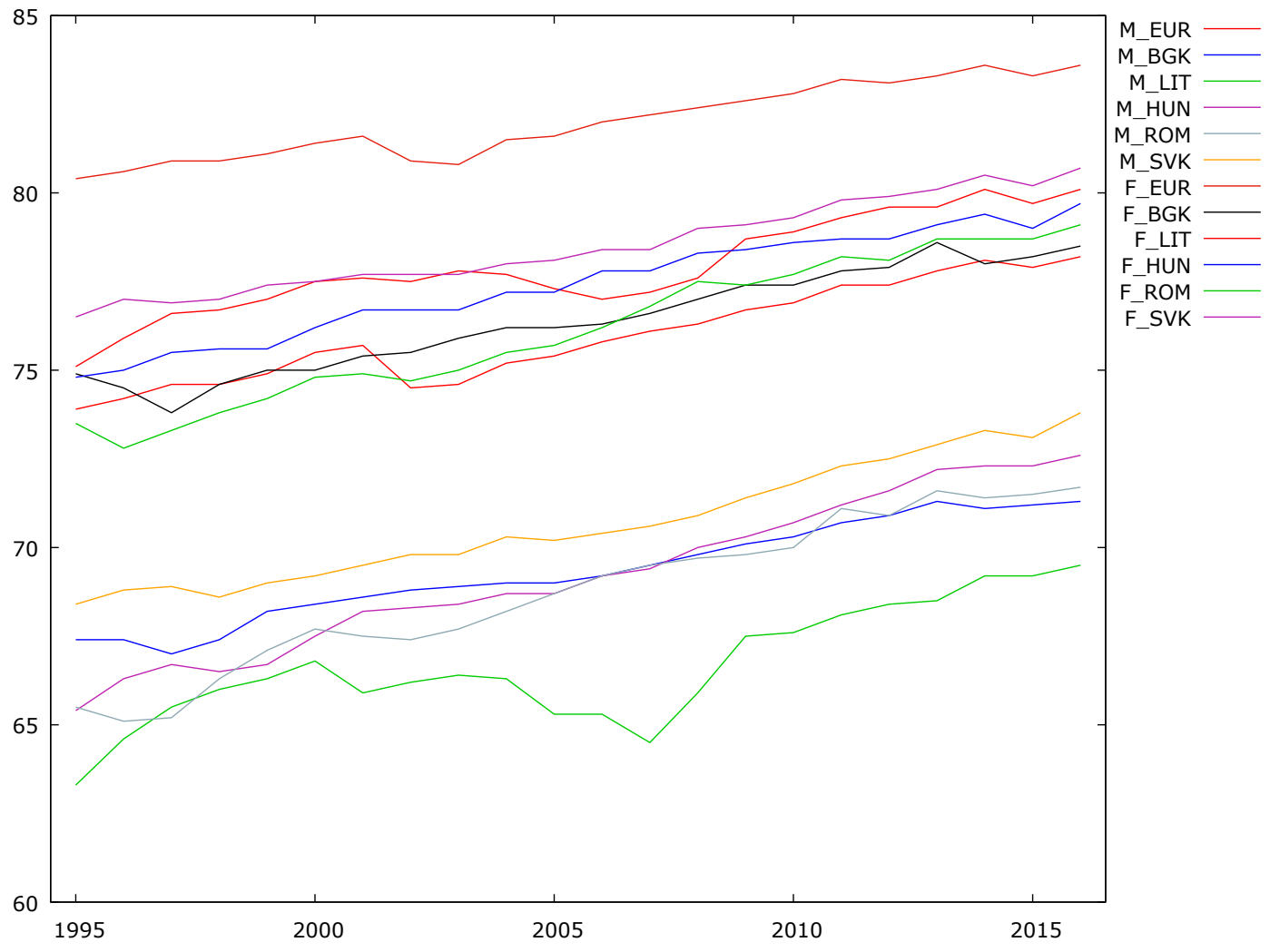

Figure 1. Time series plots for life expectancy variables

Source: Authors' own research. 
The results obtained following the application of the trend regression model are presented in table 2 .

Table 2. Trend regression for the main indicators

\begin{tabular}{|l|l|l|l|l|l|l|l|}
\hline $\begin{array}{l}\text { Variabl } \\
\text { e }\end{array}$ & time & sq_time & $\begin{array}{l}\boldsymbol{p} \text {-value } \\
\text { time }\end{array}$ & $\begin{array}{l}\boldsymbol{p} \text {-value } \\
\text { sq_time }\end{array}$ & $\begin{array}{l}\text { P- } \\
\text { value(F } \\
\text { ) }\end{array}$ & $\begin{array}{l}\text { Adjusted } \\
\text { R- } \\
\text { squared }\end{array}$ & F(2,19) \\
\hline M_EUR & 0.0902174 & 0.00489836 & $0.0515^{*}$ & $0.0218^{* *}$ & $\begin{array}{l}6.05 \mathrm{e}- \\
13\end{array}$ & $\begin{array}{l}0.92614 \\
1\end{array}$ & 174.09 \\
\hline M_BGK & 0.218415 & -0.00033173 & $\begin{array}{l}<0.0001^{* *} \\
*\end{array}$ & 0.8255 & $\begin{array}{l}2.17 \mathrm{e}- \\
14\end{array}$ & $\begin{array}{l}0.96869 \\
1\end{array}$ & 251.07 \\
\hline M_LIT & -0.0007834 & 0.00926736 & 0.9967 & 0.2059 & $\begin{array}{l}4.86 \mathrm{e}- \\
07\end{array}$ & $\begin{array}{l}0.69612 \\
2\end{array}$ & 34.38 \\
\hline M_HUN & 0.322226 & 0.000656409 & $\begin{array}{l}<0.0001^{* *} \\
*\end{array}$ & 0.6736 & $\begin{array}{l}2.30 \mathrm{e}- \\
19\end{array}$ & $\begin{array}{l}0.98528 \\
0\end{array}$ & 860.67 \\
\hline M_ROM & 0.416989 & -0.00395963 & $\begin{array}{l}<0.0001^{* *} \\
*\end{array}$ & $0.0182^{* *}$ & $\begin{array}{l}8.43 \mathrm{e}- \\
16\end{array}$ & $\begin{array}{l}0.97166 \\
1\end{array}$ & 357.35 \\
\hline M_SVK & 0.101447 & 0.00669819 & $\begin{array}{l}<0.0001^{* *} \\
*\end{array}$ & $\begin{array}{l}<0.0001^{* *} \\
*\end{array}$ & $\begin{array}{l}7.82 \mathrm{e}- \\
20\end{array}$ & $\begin{array}{l}0.98723 \\
8\end{array}$ & 965.34 \\
\hline F_EUR & 0.101595 & 0.00244212 & $0.0050^{* * *}$ & 0.1564 & $\begin{array}{l}2.46 \mathrm{e}- \\
14\end{array}$ & $\begin{array}{l}0.93140 \\
3\end{array}$ & 247.70 \\
\hline F_BGK & 0.202647 & 0.000614060 & $0.0004^{* * *}$ & 0.7809 & $\begin{array}{l}7.55 \mathrm{e}- \\
13\end{array}$ & $\begin{array}{l}0.95005 \\
3\end{array}$ & 169.85 \\
\hline F_LIT & 0.150360 & 0.00208216 & 0.1521 & 0.6212 & $\begin{array}{l}7.62 \mathrm{e}- \\
10\end{array}$ & $\begin{array}{l}0.85336 \\
9\end{array}$ & 77.10 \\
\hline F_HUN & 0.311582 & -0.00360672 & $\begin{array}{l}<0.0001^{* *} \\
*\end{array}$ & $\begin{array}{l}<0.0001^{* *} \\
*\end{array}$ & $\begin{array}{l}1.07 \mathrm{e}- \\
23\end{array}$ & $\begin{array}{l}0.98515 \\
3\end{array}$ & $\begin{array}{l}2478.5 \\
2\end{array}$ \\
\hline F_ROM & 0.326383 & -0.00083286 & $<0.0001^{* *}$ & 0.7102 & $\begin{array}{l}4.62 \mathrm{e}- \\
17\end{array}$ & $\begin{array}{l}0.97475 \\
6\end{array}$ & 488.47 \\
\hline F_SVK & 0.118979 & 0.00333851 & $\begin{array}{l}<0.0001^{* *} \\
*\end{array}$ & $0.0004^{* * *}$ & $\begin{array}{l}4.23 \mathrm{e}- \\
19\end{array}$ & $\begin{array}{l}0.98228 \\
8\end{array}$ & 806.61 \\
\hline
\end{tabular}

Source: Authors' own research.

The interpretation of data allows for outlining the variables which present a trend which is more quadratic than linear. Thus, the quadratic trend seems to apply to the variables $M \_E U R, M \_R O M, M \_S V K, F_{-} H U N$ and $F_{-} S V K . \mathrm{F}(2,19)$ displays values higher than the critical level in all cases, associated with very low $P$-value $(F)$ s, the smallest $F$ being observed in the case of Lithuania. Also, the life expectancy models for this country are associated with the lowest Adjusted R-squared.

The models for the Lithuanian variables display no trend, either linear or quadratic, even if the model tests $F$ and $P$ have proper values, the $p$-values of the two dependent variables are superior to the acceptable significance levels. European Union's life expectancies are characterized by a quadratic trend only in the case of males. The same conclusion is outlined by the characteristics of the Romanian model, while for Slovakia the quadratic trends are properly emphasized at the highest significance level.

For Bulgaria, the models, for both genders, reveal a significant linear trend, while the quadratic trend cannot be accepted at any level of significance. In Hungary, the result 
regarding the quadratic trend appears valid only for the measures corresponding to the females member of the gender dimension.

- Influence of GDP/capita, and of General government expenditure by function (COFOG), for health on Life expectancy in absolute value at birth

First, the correlation coefficients linking the three variables were tested, across the case studies approached. The values are presented in table no. 3To be noted, the actual (not differenced) values of the variables were subjected to the test, as the correlation does not involve causality.

Table 3. Correlation coefficients of factors with the main variable

\begin{tabular}{|l|c|c|l|c|c|}
\hline $\begin{array}{c}\text { Main } \\
\text { variable }\end{array}$ & $\begin{array}{c}\text { GDP per } \\
\text { capita } \\
\text { GC }\end{array}$ & $\begin{array}{c}\text { General government } \\
\text { expenditure for } \\
\text { health (HF) }\end{array}$ & $\begin{array}{c}\text { Main } \\
\text { variable }\end{array}$ & $\begin{array}{c}\text { GDP per } \\
\text { capita } \\
\text { GC }\end{array}$ & $\begin{array}{c}\text { General government } \\
\text { expenditure for } \\
\text { health (HF) }\end{array}$ \\
\hline M_EUR & 0.9124 & 0.9370 & M_LIT & 0.7828 & 0.7804 \\
\hline F_EUR & 0.9274 & 0.9522 & F_LIT & 0.8904 & 0.8878 \\
\hline M_BGK & 0.9675 & 0.9737 & M_HUN & 0.9372 & 0.8819 \\
\hline F_BGK & 0.9771 & 0.9648 & F_HUN & 0.9664 & 0.9169 \\
\hline M_ROM & 0.9497 & 0.9479 & M_SVK & 0.9657 & 0.9654 \\
\hline F_ROM & 0.9753 & 0.9744 & F_SVK & 0.9737 & 0.9734 \\
\hline
\end{tabular}

It can be observed from the values of the coefficients that the three variables are correlated in a strong manner. The weakest links are in the case of Lithuania (males and, to a lesser extent, females). This is correlated to the values of the other tests applied on the variables. There cannot be established a generalized hierarchy of the two influence factors. A fact that must be outlined is that the levels of the correlation coefficients are higher in the case of female-oriented data, with a single exception, $H F$ variable in Bulgaria.

The results of the regression models' estimation are presented in the table no. 4 (regressions for EU, Bulgaria and Romania) and table 5 (for the $2^{\text {nd }}$ order differencing, Hungary, Lithuania and Slovakia):

Table 4. Multiple regression, selected factors included

\begin{tabular}{|l|l|l|l|l|l|l|l|}
\hline $\begin{array}{l}\text { Variabl } \\
\text { e } \\
\text { (as first } \\
\text { diff.) }\end{array}$ & $\begin{array}{l}\text { GDP per } \\
\text { capita } \\
\text { GC }\end{array}$ & $\begin{array}{l}\text { General } \\
\text { government } \\
\text { expenditure } \\
\text { for health (HF) }\end{array}$ & $\begin{array}{l}\boldsymbol{p} \text {-value } \\
\text { GC }\end{array}$ & $\begin{array}{l}\boldsymbol{p} \text { - } \\
\text { value } \\
\boldsymbol{H F}\end{array}$ & $\begin{array}{l}\text { P- } \\
\text { value(F) }\end{array}$ & $\begin{array}{l}\text { Adjusted } \\
\text { R- } \\
\text { squared }\end{array}$ & F \\
\hline M_EUR & $2.75050 \mathrm{e}-05$ & $4.30230 \mathrm{e}-06$ & 0.7998 & 0.2640 & 0.107187 & 0.109828 & 2.517495 \\
\hline F_EUR & $4.55439 \mathrm{e}-05$ & $2.75170 \mathrm{e}-06$ & 0.5506 & 0.287 & 0.08789 & 0.11966 & 2.77119 \\
& & & 6 & 2 & 8 & 5 \\
\hline M_BGK & 0.00014222 & -0.00025633 & 0.3835 & 0.353 & 0.45962 & -0.06083 & 0.81190 \\
& 7 & 6 & & 1 & 5 & & 1 \\
\hline F_BGK & 0.00059916 & -0.00065619 & $0.0085^{* *}$ & 0.243 & 0.04800 & 0.14488 & 3.61146 \\
& 9 & 7 & 5 & 6 & 5 & 9 \\
\hline M_ROM & 0.00018679 & 0.000243116 & 0.5240 & 0.484 & 0.04741 & 0.19100 & 3.59488 \\
& 6 & & 4 & 4 & 8 & 3 \\
\hline F_ROM & 0.00040379 & $9.82938 \mathrm{e}-05$ & $0.0123^{* *}$ & 0.626 & $2.89 \mathrm{e}-07$ & 0.41889 & 36.8557 \\
& 8 & & 5 & & 7 & 8 \\
\hline
\end{tabular}


In the European Union, none of the independent variables prove to be statistically significant, with an Adjusted R-Squared that displays a low possibility to explain the modification of the life expectancy through the chosen economic factors (close to $11 \%$ for men and slightly lower than 12 in the case of women).

For Bulgaria, the model for males' dataset does not explain any influence of the factors considered. High $p$-value substantiates this observation. According to the second model, 14\% of the evolution of the first difference of life expectancy can be explained by the evolution of GDP per capita. For each unit increase of the GC parameter, the life expectancy of Bulgarian women accelerates by almost 0.0006 years, acceptable at a level of significance of $1 \%$. The $p$ value of the model is also low enough, while the $F$ parameter is higher than the table value (at $5 \%$ confidence). This is a reasonable level and can be considered a positive result, which comes in line with the results of Wang et al. (2014) and Cole (2019). Also, in the model, the $H F$ parameter, even if not statistically significant (its $p$-value is very high) displays a negative influence, which should not be considered normal.

The Romanian model for women can explain, at a confidence level of $5 \%$, in a proportion of almost $42 \%$, by the acceleration of the GDP/capita, the evolution, in the same way, of the life expectancy. There is a favorable contribution, of over 0.0004 years acceleration for each unit of $\Delta$ GDP per capita increase.

For the variables in table 5 , subjected to $2^{\text {nd }}$ differences, the models prove to be less than significant. Even if the Lithuanian models are characterized by low p-values, the $F$ test is greater than the reference value only in the case of women. The factors' influences, characterized by the regression coefficients, are not positive.

Table 5. Multiple regression, selected factors included

\begin{tabular}{|l|l|l|l|l|l|l|l|}
\hline $\begin{array}{l}\text { Variable } \\
\text { (as 2 } \\
\text { diff.) }\end{array}$ & $\begin{array}{l}\text { GDP per capita } \\
\text { GC }\end{array}$ & $\begin{array}{l}\text { General } \\
\text { government } \\
\text { expenditure } \\
\text { for health (HF) }\end{array}$ & $\begin{array}{l}\boldsymbol{p} \text {-value } \\
\text { GC }\end{array}$ & $\begin{array}{l}\boldsymbol{p} \text {-value } \\
\text { HF }\end{array}$ & $\begin{array}{l}\text { P- } \\
\text { value(F) }\end{array}$ & $\begin{array}{l}\text { Adjusted } \\
\text { R- } \\
\text { squared }\end{array}$ & F \\
\hline M_LIT & -0.000117245 & -0.00166374 & 0.5620 & 0.2474 & 0.003841 & 0.090908 & 0.138755 \\
\hline F_LIT & $-8.62194 \mathrm{e}-05$ & -0.00110873 & 0.4858 & 0.1347 & 0.015074 & 0.167597 & 5.343668 \\
\hline M_HUN & $7.19781 \mathrm{e}-05$ & -0.000195697 & 0.4802 & 0.2416 & 0.516414 & -0.00768 & 0.685714 \\
\hline F_HUN & 0.000181625 & -0.000500791 & 0.3520 & 0.1619 & 0.379895 & 0.131950 & 1.021819 \\
\hline M_SVK & $-8.26360 \mathrm{e}-05$ & -0.000251309 & 0.4149 & 0.3861 & 0.118345 & 0.030591 & 0.081613 \\
\hline F_SVK & $-4.92489 \mathrm{e}-05$ & 0.000344768 & 0.7275 & 0.3552 & 0.644757 & 0.010678 & 0.449758 \\
\hline
\end{tabular}

Thus, the independent variables pose no real influence on the life expectancy, in any of the case studies and it should direct to future research based on the application of other methods.

\section{Conclusion}

In the cases where the influence is proven to be statistically significant, it is normal (negative associated to emissions), but positive in the other cases. Thus, the research hypotheses are partially validated by the data analysis. 
There were several major limitations for the study. On one hand, the datasets were chosen according to the formulated hypotheses, and correlated across the time dimension, in order to achieve better consistency. The use of more detailed datasets might offer improved results in future researches. Given the statistical nature of the variables, the regression method chosen and applied does not reveal significant results, either as favorable or nonfavorable influences, with some exceptions, even if differences were used, as they reflect the way the independent variable accelerates (or slows down) over time.

On the other hand, the main objective of this study was to measure the influence of macroeconomic indicators on the life expectancy of the population. But the health status of the population is correlated not only with life expectancy, but also with the quality of life. For this reason, the psycho-sociologist Jacques Salome described aging in our modern societies as follow: "Aging means not only adding years to our lives, but also life to our years." Unfortunately, the quality of life is difficult to be quantified, often being expressed in present through subjective factors.

Finally, the accuracy of reporting data, and also the health education of the population (which may vary in great extent from one country to another), must be taken into consideration.

The authors therefore suggest for the future research efforts to be dedicated to the study of the hypotheses in close relation with the above mentioned/ relevant factors, which could influence the health status of population.

\section{References}

Asandului, L., Roman, M., \& Fatulescu, P. (2014). The Efficiency of Healthcare Systems in Europe: A Data Envelopment Analysis Approach. Procedia Economics and Finance, 10, 261-268.

Asiskovitch, S. (2010). Gender and health outcomes: The impact of healthcare systems and their financing on life expectancies of women and men. Social Science \& Medicine, $70(6), 886-895$.

Boudoulas, K. D., Triposkiadis, F., Stefanadis, C., \& Boudoulas, H. (2017). The endlessness evolution of medicine, continuous increase in life expectancy and constant role of the physician. Hellenic Journal of Cardiology, 58(5), 322-330.

Cole, W.M. (2019). Wealth and health revisited: Economic growth and wellbeing in developing countries, 1970 to 2015. Social Science Research, 77, 45-67.

Echevarría, C. A., \& Iza, A. (2006). Life expectancy, human capital, social security and growth. Journal of Public Economics, 90(12), 2323-2349.

Hauck , K., Martin, S., \& Smith, P. C. (2016). Priorities for action on the social determinants of health: Empirical evidence on the strongest associations with life expectancy in 54 low-income countries, 1990-2012. Social Science \& Medicine, 167, 88-98.

Jaba, E., Balan, C. B., \& Robu, I.B. (2014). The Relationship between Life Expectancy at Birth and Health Expenditures Estimated by a Cross-country and Time-series Analysis. Procedia Economics and Finance, 15, 108-114.

Linden, M., \& Ray, D. (2017). Life expectancy effects of public and private health expenditures in OECD countries 1970-2012: Panel time series approach. Economic Analysis and Policy, 56, 101-113. 
Obrizan, M., \& Wehby, G. L. (2018). Health Expenditures and Global Inequalities in Longevity. World Development, 101, 28-36.

Parker, J.A. Chapter 4. Regression with Nonstationary Variables. Retrieved from https://www.reed.edu/economics/parker/312/tschapters/S13_Ch_4.pdf .

van den Heuvel, W. J. A., \& Olaroiu, M. (2017). How Important Are Health Care Expenditures for Life Expectancy? A Comparative, European Analysis. Journal of the American Medical Directors Association, 18(3), 276.e9-276.e12.

Wang, S., Luo, K., Liu, Y., Zhang, S., \& Gao X. (2015). Economic level and human longevity: Spatial and temporal variations and correlation analysis of per capita GDP and longevity indicators in China. Archives of Gerontology and Geriatrics, 61(1), 93-102.

Woolridge, J.M. (2012). Introductory Econometrics: A Modern Approach, Fifth Edition. Retrived

from http://economics.ut.ac.ir/documents/3030266/14100645/Jeffrey_M._Wooldridge_I ntroductory_Econometrics_A_Modern_Approach_2012.pdf

Xinming S., Gong C. \& Xiaoying Z., (2010), Chinese Life Expectancy and Policy Implications, Procedia - Social and Behavioral Sciences, Volume 2, Issue 5, 2010, Pages 7550-7555 